\title{
PENGAPLIKASIAN JOB SAFETY ANALYSIS (JSA) DAN METODE RAPID UPPER LIMB ASSESSMENT (RULA) PADA PEKERJAAN MANUAL HANDLING
}

\author{
Friska Eka Fitria ${ }^{1 *}$, Dina Waldani, ${ }^{2 *}$ Wenny Murdina Asih ${ }^{3 *}$ \\ ${ }^{1,2,3}$ Program Studi Hiperkes dan Keselamatan Kerja, Sekolah Tinggi Ilmu Kesehatan Indonesia, Jln. Khatib \\ Sulaiman No. 17, Kel. Lolong Belanti Kec. Padang Utara Kota Padang \\ friskaekafitria@gmail.com
}

\begin{abstract}
Manual Handling is the process of lifting, moving, placing, pushing, pulling, sliding, and supporting loads with the hands and body. There are 5 work processes at PT. Aura Mandiri Sejahtera still manually which is identified as an ergonomic hazard due to a mismatch between the tool or machine and the posture of the workers. The 5 work processes are the Stone Retrieval Process, the Stone Collection Process, the Stone Lifting Process to the Car Body, the Sand Extraction Process, and the Sand Lifting Process to the Car Body. The purpose of this study was to identify the hazards of manual handling work using JSA and to assess the risks of manual handling work using the RULA method at PT. Aura Mandiri Sejahtera. This type of research is a qualitative descriptive research was conducted from February to August 2021 at PT. Aura Mandiri Sejahtera. The results showed that from 5 manual handling work processes at PT. Aura Mandiri Sejahtera there are 5 ergonomic hazards identified using JSA and when a work risk assessment is carried out using the RULA method, it is found 4 work process with a score of 7 that means efforts must be made to change the work process immediately. for change efforts are expected to the leadership of PT. Aura Mandiri Sejahtera carries out work risk control by modifying work tools in the form of providing or replacing work equipment in accordance with the worker's body posture.
\end{abstract}

Keywords: JSA; RULA; Modifying work tools

ABSTRAK

Manual Handling merupakan proses Pengangkatan, Memindahkan, Meletakkan, Mendorong, Menarik, Menggeser, dan Penyanggaan beban dengan tangan dan tubuh. Terdapat 5 proses pekerjaan di PT. Aura Mandiri Sejahtera yang masih dilakukan secara manual yang teridentifikasi sebagai bahaya ergonomi dikarenakan ketidaksesuaian antara alat atau mesin dengan postur para pekerja. 5 proses pekerjaan tersebut yaitu Proses Pengambilan Batu, Proses Pengumpulan Batu, Proses Pengangkatan Batu ke Bak Mobil, Porses Pengambilan Pasir, dan Proses Pengangkatan Pasir ke Bak mobil. Tujuan dari penelitian ini adalah untuk mengidentifikasi bahaya pekerjaan manual handling menggunaan JSA serta menilai risiko pekerjaan Manual Handling menggunakan metode RULA di PT. Aura Mandiri Sejahtera. Jenis penelitian ini adalah Penelitian Deskriptif Kualitatif yang dilakukan bulan Februari sampai dengan Agustus 2021 di PT. Aura Mandiri Sejahtera. Hasil Penelitian menunjukkan bahwa dari 5 proses pekerjaan Manual Handling di PT. Aura Mandiri Sejahtera terdapat 5 bahaya ergonomi yang teridentikasi menggunakan JSA serta ketika 
Friska Eka Fitria, Dina Waldani, Wenny Murdina Asih | PENGAPLIKASIAN JOB SAFETY ANALYSIS (JSA) DAN METODE RAPID UPPER LIMB ASSESSMENT (RULA) PADA PEKERJAAN MANUAL HANDLING

dilakukan penilaian risiko kerja menggunakan metode RULA didapatkan bahwa terdapat 4 proses pekerjaan dengan Skor 7 yang artinya harus segera dilakukan upaya perubahan terhadap proses kerja pekerjaan tersebut. untuk upaya perubahan diharapkan kepada pimpinan PT. Aura Mandiri Sejahtera melakukan pengendalian risiko kerja dengan cara modifikasi alat Pekerjaan dalam bentuk penyediaan atau penggantian peralatan pekerjaan yang sesuai dengan postur tubuh pekerja.

Kata Kunci: JSA; RULA; Modifikasi peralatan pekerjaan

\section{PENDAHULUAN}

Salah satu masalah di dunia industri dengan pengaruh besar saat ini adalah masalah ergonomi. Masalah ini muncul dikarenakan alat atau mesin industri yang digunakan tidak sesuai dengan postur pekerja dan aktivitas pemindahan material secara manual masih menjadi sebagian besar aktivitas yang ada di dunia industri seperti aktivitas pengangkatan, penurunan, mendorong, menarik, mengangkut dan memindahkan barang. Apabila pekerjaan tidak dilakukan secara ergonomis maka akan menimbulkan kecelakaan kerja dalam industri (Salcha et al., 2020)

Ergonomi sebagai salah satu ilmu yang berusaha untuk menyerasikan antara faktor manusia, faktor pekerjaan dan faktor lingkungan. Dengan bekerja secara ergonomis diperoleh rasa nyaman dalam bekerja, terhindarnya kelelahan, terhindar dari gerakan dan upaya yang tidak perlu serta upaya melaksanakan pekerjaan menjadi lebih ringan dengan hasil yang sebesar-besarnya. Upaya pencapaian keselamatan dan kesehatan kerja tidak lepas dari peran ergonomi, karena ergonomi berkaitan dengan orang yang bekerja, selain dalam rangka efektivitas dan efisiensi kerja(Bortolini et al., 2018)

Pekerjaan manual handling merupakan pekerjaan pemindahan material secara manual, yang terdiri dari aktivitas mengangkat, menurunkan, mendorong, menarik dan membawa beban dengan menggunakan tangan dan tubuh. Akibat yang ditimbulkan dari aktivitas Manual Handling yang tidak benar salah satunya adalah keluhan muskoloskeletal, yaitu keluhan pada bagian-bagian otot skeletal yang dirasakan oleh seseorang mulai dari keluhan yang sangat ringan sampai sangat sakit.(Siska \& Angrayni, 2018)

Job Safety Analysis (JSA) merupakan suatu metode yang digunakan untuk melakukan identifikasi bahaya pekerjaan setiap proses kerja sampai dengan menentukan pengendalian yang sesuai dengan proses kerja tersebut. (Irennius et al., 2020)

Rapid Upper Limb Assessment (RULA) adalah metode yang dikembangkan dalam bidang ergonomi yang menginvestigasi dan menilai posisi kerja yang dilakukan oleh tubuh bagian atas. Penilaian dengan menggunakan RULA membutuhkan waktu guna mendapatkan scoring general pada daftar aktivitas yang mengindikasikan perlu adanya pengurangan risiko diakibatkan pengangkatan fisik yang dilakukan pekerja. Metode RULA diperuntukan pada bidang ergonomi dan bidang cakupan yang luas.(Siska \& Angrayni, 2018)

PT. Aura Mandiri Sejahtera terletak di Jorong Ladang Panjang Nagari Ladang Panjang, Kecamatan Tigo Nagari, Kabupaten Pasaman. Perusahaan ini bergerak dalam usaha/kegiatan Asphalt Mixing Plan (AMP) dan Batching Paln (BP). Perusahaan ini memproduksi Asphalt Mixing Plan (AMP) dan Batching Paln (BP) 200-300 ton/hari, Batching Plan (BP) $100 \mathrm{~m}^{3} / \mathrm{jam}$. Dalam proses kerjanya, terdapat 2 jenis pekerjaan yang dilakukan secara manual, yaitu kegiatan pemecahan batu serta kegiatan memuat pasir. 2 jenis pekerjaan tersebut dibagi kedalam 5 proses pekerjaan yaitu proses pengambilan 
batu, proses pengumpulan batu, proses pengangkatan batu ke bak mobil, proses pengambilan pasir, dan proses pengangkatan pasir ke bak mobil. Guna mengidentifikasi bahaya dan risiko setiap proses pekerjaan maka penulis akan melakukan JSA Pekerjaan, sedangkan guna melihat seberapa besar risiko pekerjaan bagian atas penulis menggunakan Metode RULA yang mana nanti akan didapatkan scoring general pada daftar aktivitas yang mengindikasikan perlu adanya pengurangan risiko diakibatkan pengangkatan fisik yang dilakukan pekerja.

Berdasarkan hal diatas, maka peneliti akan mengaplikasikan metode Job Safety Analysis (JSA) dan Rapid Upper Limb Assessment (RULA) pada Pekerjaan Manual Handling di PT. Aura Mandiri Sejahtera.

\section{METODE PENELITIAN}

Jenis penelitian ini adalah Kualitatif dengan pendekatan deskriptif. Lokasi penelitian di PT. Aura Mandiri Sejahtera dan penelitian ini dilakukan pada bulan Februari sampai Juli Tahun 2021.

Objek yang diteliti adalah proses kerja pada pekerja lapangan bagian pemuat batu dan pasir dengan aktivitas Manual Handling yang kemudian dinilai menggunakan Tabel JSA dan worksheet RULA.

Teknik pengumpulan data dengan observasi langsung ke lapangan, wawancara, dan pengukuran sikap kerja untuk mengetahui bahaya dan risiko setiap proses pekerjaan dan melihat sikap kerja agar didapatkan scoring general pada daftar aktivitas yang mengindikasikan perlu adanya pengurangan risiko diakibatkan pengangkatan fisik yang dilakukan pekerja.

Tahapan pengolahan data Pada penggunaan metode JSA dilakukan penulis dengan membuat tabel JSA yang mana pada table tersebut terdapat urutan tahapan pekerjaan, bahaya dan risiko pekerjaan, dan bentuk pengendalian pekerjaan yang direkomendasikan. Pada penggunaan metode RULA penulis mengolah data dengan cara yang pertama adalah melakukan Identifikasi Postur Kerja menggunakan hasil capture sikap kerja saat melakukan akitivitas Manual Handling. Langkah selanjutnya adalah Menggunakan data Worksheet RULA untuk mengukur postur kerja dengan cara: Membagi pengamatan tubuh pekerja kedalam 2 grup, yaitu A yang terdiri dari lengan atas (upper arm), lengan bawah (lower arm), pergelangan tangan (wirst), serta mengukur beban (load/force) dan skor aktivitas. B terdiri dari leher (neck), kaki (leg), batang tubuh dan Menilai setiap sikap kerja saat melakukan aktivitas Manual Handling menggunakan Worksheet RULA kedalam skor A dan skor B. Setelah itu peneliti menentukan skor Worksheet RULA dari hasil kombinasi perhitungan skor A dan skor B. Yang terakhir peneliti Menentukan action level dari postur kerja saat melakukan aktivitas Manual Handling.

\section{HASIL DAN PEMBAHASAN}

Hasil penelitian terhadap penilaian proses pekerjaan menggunakan Metode JSA dapat dilihat pada table dibawah ini: 


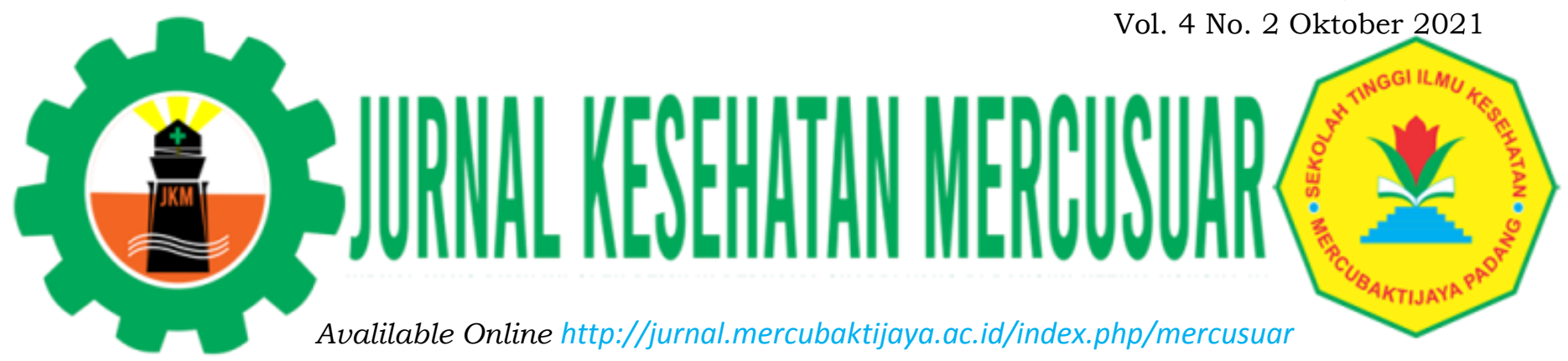

\section{Tabel 1. Pengaplikasian Metode JSA Pada Setiap Proses Pekerjaan Hasil Penilaian JSA}

\begin{tabular}{|c|c|c|c|c|c|}
\hline No & $\begin{array}{c}\text { Tahap } \\
\text { Pekerjaan }\end{array}$ & Bahaya & Dokumentasi & Risiko & Pengendalian \\
\hline 1. & $\begin{array}{l}\text { Proses } \\
\text { Pengambilan } \\
\text { Batu }\end{array}$ & $\begin{array}{l}\text { Ergonomi } \\
\text { (Pekerjaan } \\
\text { berulang } \\
\text { dengan } \\
\text { proses } \\
\text { membungk } \\
\text { uk ke tegap } \\
\text { ataupun } \\
\text { sebaliknya } \\
\text { ketika } \\
\text { mengambil } \\
\text { batu ) }\end{array}$ & & $\begin{array}{l}\text { Beban yang } \\
\text { berat dapat } \\
\text { menyebabkan } \\
\text { penyakit akibat } \\
\text { kerja seperti } \\
\text { gangguan pada } \\
\text { otot yang } \\
\text { meliputi } \\
\text { tangan,punggun } \\
\text { g dan bagian } \\
\text { tubuh lainnya } \\
\text { serta dapat } \\
\text { menyebabkan } \\
\text { kecelakaan kerja } \\
\text { dikarenakan } \\
\text { pekerja tidak } \\
\text { sanggup } \\
\text { menopang beban } \\
\text { yang berat } \\
\text { sehingga batu } \\
\text { yang diangkat } \\
\text { jatuh dan } \\
\text { mengenai kaki } \\
\text { pekerja. }\end{array}$ & $\begin{array}{l}\text { 1. Memberikan } \\
\text { fasilitas alat } \\
\text { bantu agar } \\
\text { pekerja terhindar } \\
\text { dari penyakit } \\
\text { akibat kerja dan } \\
\text { kecelakaan kerja } \\
\text { (administrasi). } \\
\text { 2.Menggunakan } \\
\text { alat pelindung } \\
\text { diri (APD) } \\
\text { seperti hand } \\
\text { gloves dan safety } \\
\text { shoes agar aman } \\
\text { saat melakukan } \\
\text { pekerjaan. }\end{array}$ \\
\hline 2. & $\begin{array}{l}\text { Proses } \\
\text { Pengumpulan } \\
\text { Batu }\end{array}$ & $\begin{array}{l}\text { Ergonomi } \\
\text { (Pekerjaan } \\
\text { berulang } \\
\text { dengan } \\
\text { proses } \\
\text { mengangkut } \\
\text { batu ke } \\
\text { tempat } \\
\text { pengumpula } \\
\text { n batu ) }\end{array}$ & & $\begin{array}{l}\text { Beban yang } \\
\text { berat dapat } \\
\text { menyebabkan } \\
\text { penyakit akibat } \\
\text { kerja seperti } \\
\text { gangguang pada } \\
\text { otot yang } \\
\text { meliputi } \\
\text { tangan,punggun } \\
\text { g dan bagian } \\
\text { tubuh lainnya } \\
\text { serta posisi } \\
\text { pekerja tidak } \\
\text { ergonomis saat } \\
\text { melakukan } \\
\text { proses }\end{array}$ & $\begin{array}{l}\text { 1. Memberikan } \\
\text { fasilitas alat } \\
\text { bantu yang } \\
\text { sesuai dengan } \\
\text { postur tubuh } \\
\text { pekerja agar } \\
\text { terhindar dari } \\
\text { penyakit akibat } \\
\text { kerja dan } \\
\text { kecelakaan kerja } \\
\text { (administrasi). } \\
\text { 2.Menggunakan } \\
\text { alat pelindung } \\
\text { diri (APD) } \\
\text { seperti hand } \\
\text { gloves dan safety }\end{array}$ \\
\hline
\end{tabular}




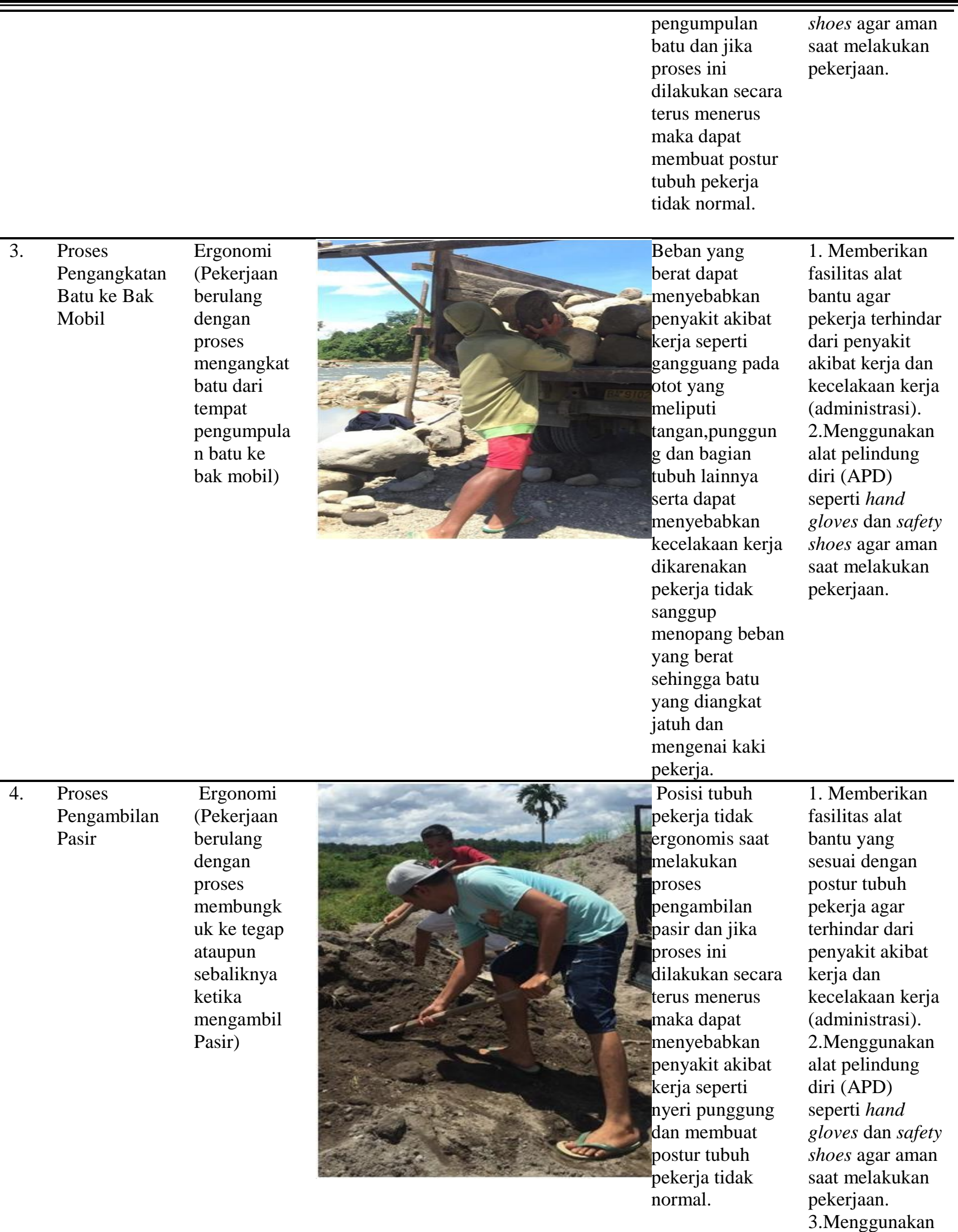


alat pelindung

diri (APD)

seperti masker

yang sesuai

dengan standar

agar aman saat

melakukan

pekerjaan dan

terhindar dari

penyakit akibat

kerja.

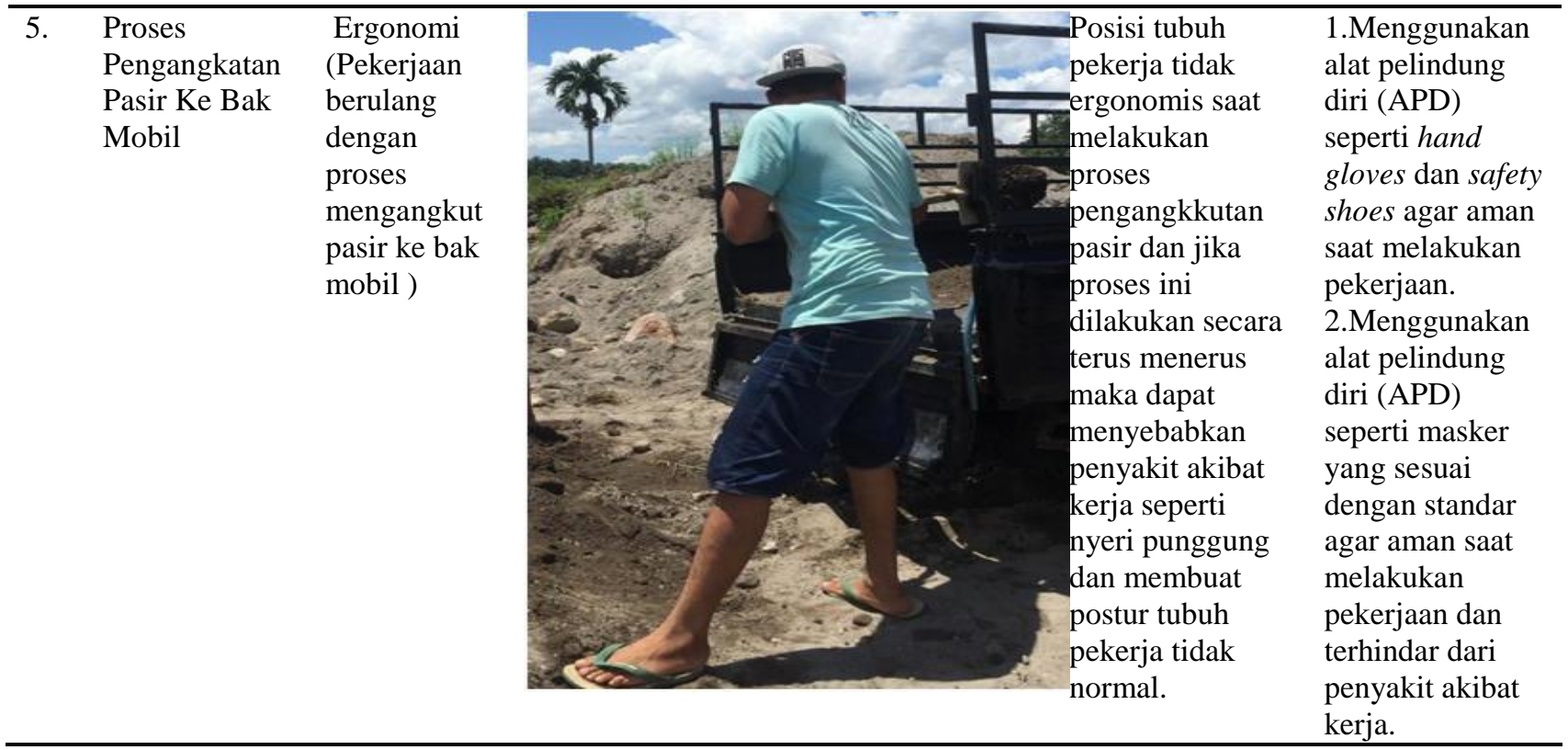

Berdasarkan tabel diatas dapat dilihat 5 proses pekerjaan di PT. Aura Mandiri Sejahtera yang masih dilakukan secara manual. Pada setiap proses pekerjaan peneliti melampirkan bukti observasi pekerjaan sehingga dapat terlihat jelas bahaya yang teridentifikasi pada masing-masing proses pekerjaan adalah bahaya ergonomi. Risiko pekerjaan yang ditimbulkan adalah Gangguan Otot Bagian Atas. Setelah pengaplikasian metode JSA, peneliti menggunakan metode RULA untuk menilai sikap kerja berdasarkan postur pekerja saat melakukan pekerjaan.

Tabel 2. Pengaplikasian Metode RULA Pada Setiap Proses Pekerjaan

\begin{tabular}{|c|c|c|c|c|c|c|}
\hline No. & Tahap Pekerjaan & & & Skor RUL & & \\
\hline 1. & $\begin{array}{l}\text { Proses } \\
\text { Pengambilan } \\
\text { Batu }\end{array}$ & No & Gambar & Variabel & Skor & Keterangan \\
\hline
\end{tabular}


Friska Eka Fitria, Dina Waldani, Wenny Murdina Asih | PENGAPLIKASIAN JOB SAFETY ANALYSIS (JSA) DAN METODE RAPID UPPER LIMB ASSESSMENT (RULA) PADA PEKERJAAN MANUAL HANDLING

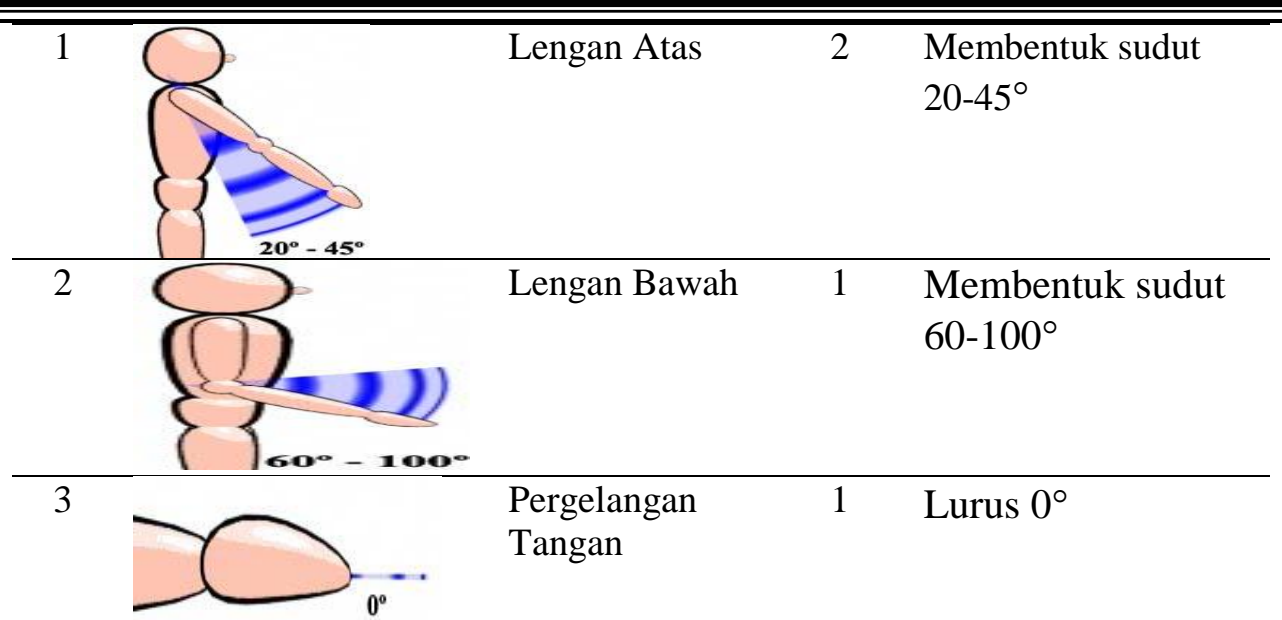

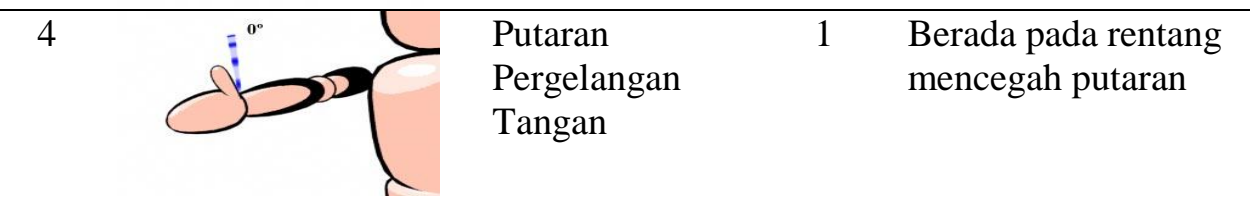

\begin{tabular}{lll} 
Leher & 4 & In Extension 20 \\
\hline
\end{tabular}

\begin{tabular}{|c|c|c|c|c|c|}
\hline Proses & No & Gambar & Variabel & Skor & Keterangan \\
\hline $\begin{array}{l}\text { Pengumpulan } \\
\text { Batu }\end{array}$ & 1 & & $\begin{array}{l}\text { Lengan } \\
\text { Atas }\end{array}$ & 3 & $\begin{array}{l}\text { Membentuk } \\
\text { sudut } 45-90^{\circ}\end{array}$ \\
\hline
\end{tabular}


Friska Eka Fitria, Dina Waldani, Wenny Murdina Asih | PENGAPLIKASIAN JOB SAFETY ANALYSIS (JSA) DAN METODE RAPID UPPER LIMB ASSESSMENT (RULA) PADA PEKERJAAN MANUAL HANDLING

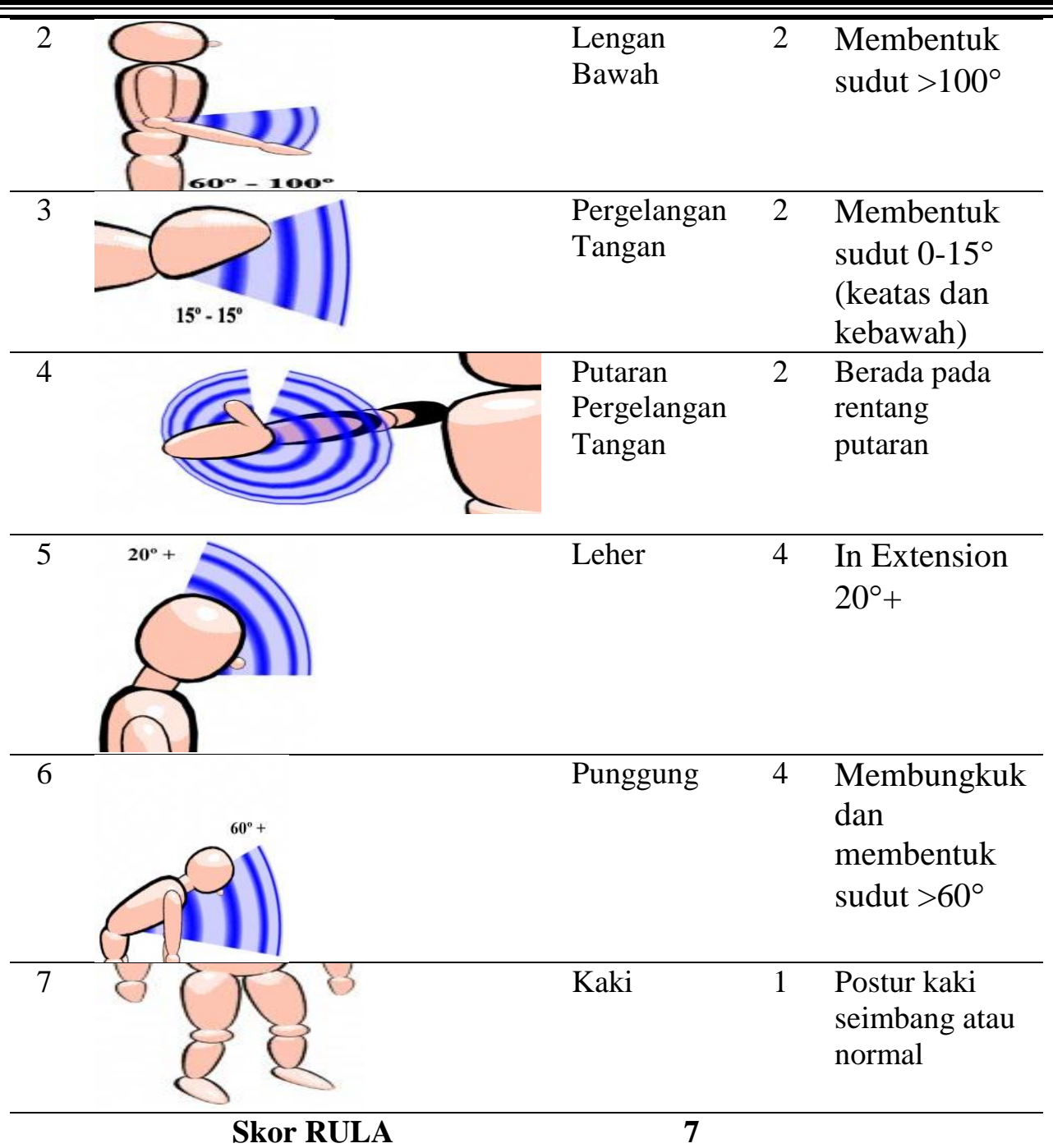

\begin{tabular}{lllll}
\hline 3. $\begin{array}{l}\text { Proses } \\
\text { Pengangkatan } \\
\text { Batu ke Bak } \\
\text { Mobil }\end{array}$ & No & Variabel & Skor & Keterangan \\
\cline { 2 - 5 } & & Lambar Atas & 2 & $\begin{array}{l}\text { Membentuk sudut } \\
20-45^{\circ}\end{array}$ \\
\hline
\end{tabular}


Friska Eka Fitria, Dina Waldani, Wenny Murdina Asih | PENGAPLIKASIAN JOB SAFETY ANALYSIS (JSA) DAN METODE RAPID UPPER LIMB ASSESSMENT (RULA) PADA PEKERJAAN MANUAL HANDLING

3
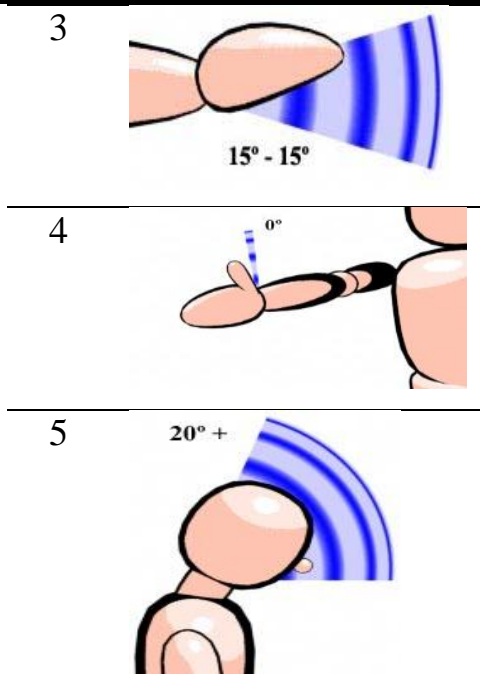

Pergelangan

Tangan

2 Membentuk sudut $15^{\circ}$ (kedepan maupun kebelakang)

\section{Putaran} Pergelangan

Tangan

Leher

4 In Extension $20^{\circ}+$

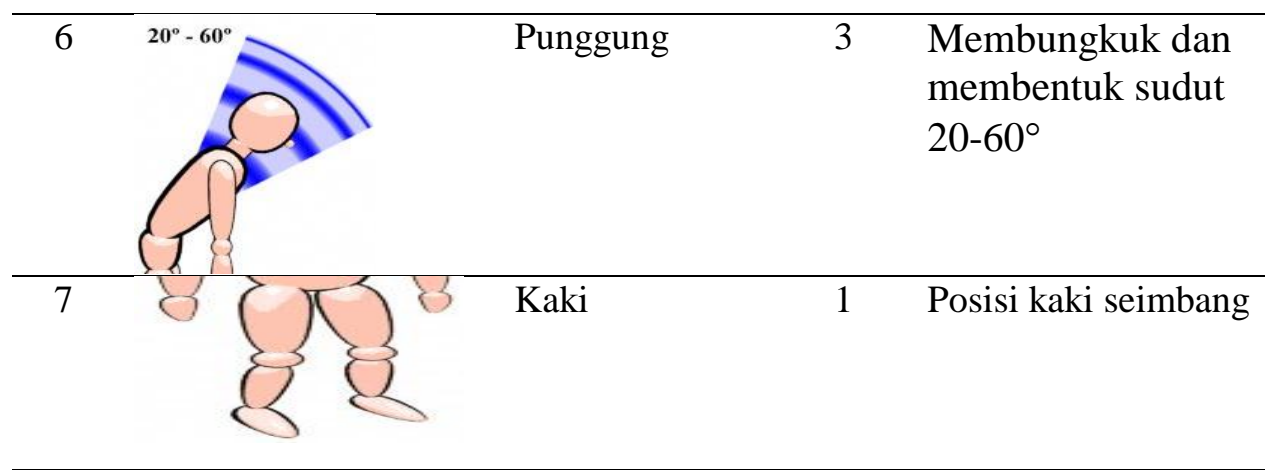

Skor RULA

7

\begin{tabular}{lllll}
\hline 4. Proses \\
Pengambilan \\
Pasir
\end{tabular}


Friska Eka Fitria, Dina Waldani, Wenny Murdina Asih | PENGAPLIKASIAN JOB SAFETY ANALYSIS (JSA) DAN METODE RAPID UPPER LIMB ASSESSMENT (RULA) PADA PEKERJAAN MANUAL HANDLING

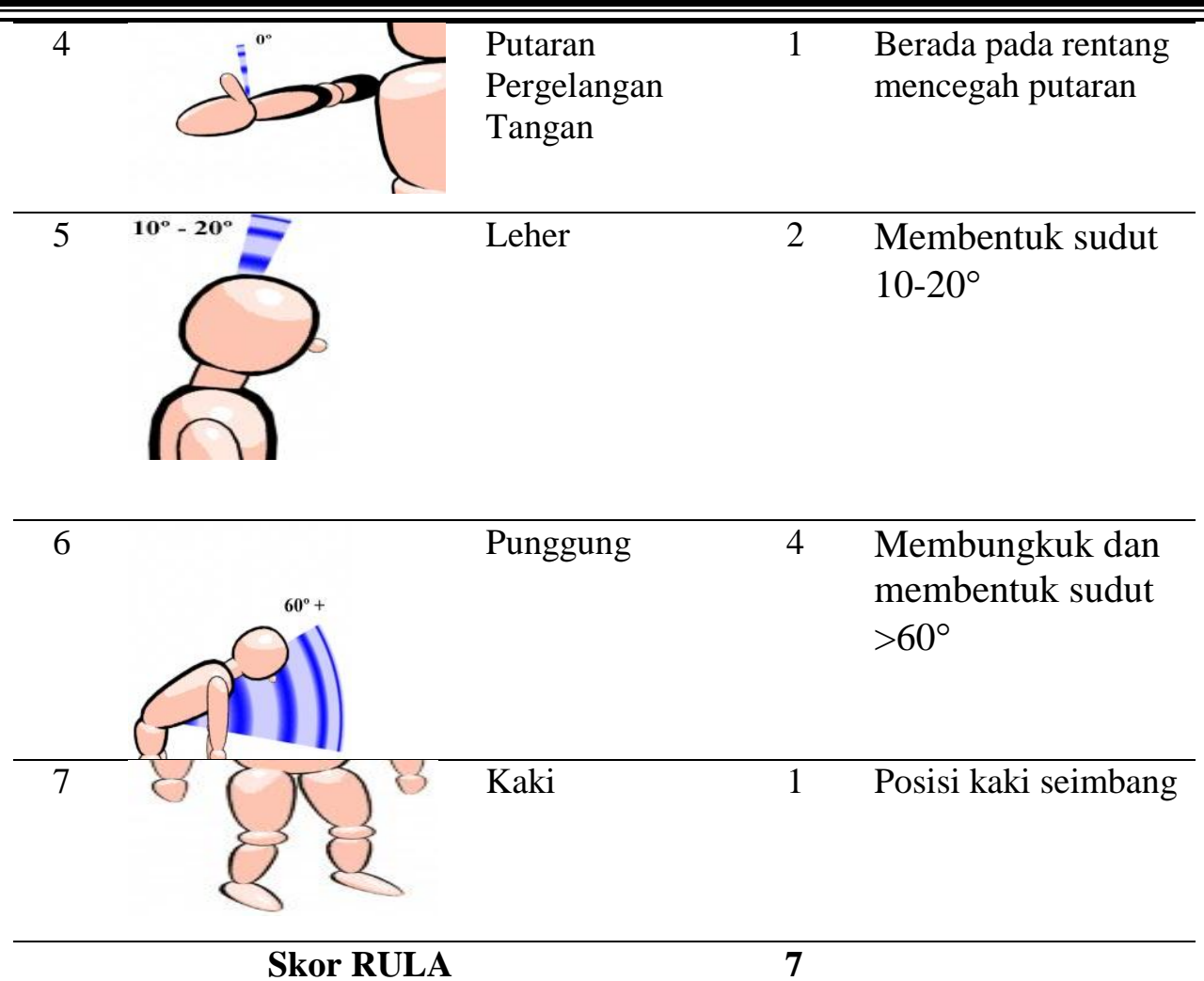

\begin{tabular}{|c|c|c|c|c|c|c|}
\hline \multirow{5}{*}{\multicolumn{2}{|c|}{$\begin{array}{ll}5 . & \text { Proses } \\
& \text { Pengangkatan } \\
& \text { Pasir Ke Bak } \\
& \text { Mobil }\end{array}$}} & No & Gambar & Variabel & Skor & Keterangan \\
\hline & & 1 & & Lengan Atas & 2 & $\begin{array}{l}\text { Membentuk sudut } \\
20-45^{\circ}\end{array}$ \\
\hline & & 2 & & Lengan Bawah & 1 & $\begin{array}{l}\text { Membentuk sudut } \\
60-100^{\circ}\end{array}$ \\
\hline & & 3 & & $\begin{array}{l}\text { Pergelangan } \\
\text { Tangan }\end{array}$ & 2 & $\begin{array}{l}\text { Membentuk sudut } \\
15^{\circ} \text { (kedepan } \\
\text { maupun } \\
\text { kebelakang) }\end{array}$ \\
\hline & & 4 & & $\begin{array}{l}\text { Putaran } \\
\text { Pergelangan } \\
\text { Tangan }\end{array}$ & 1 & $\begin{array}{l}\text { Berada pada rentang } \\
\text { mencegah putaran }\end{array}$ \\
\hline
\end{tabular}




\section{5}

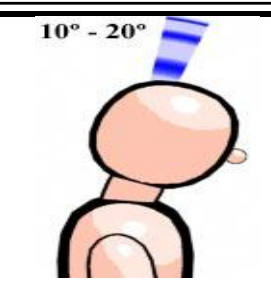

Leher
$2 \quad$ Membentuk sudut
$10-20^{\circ}$

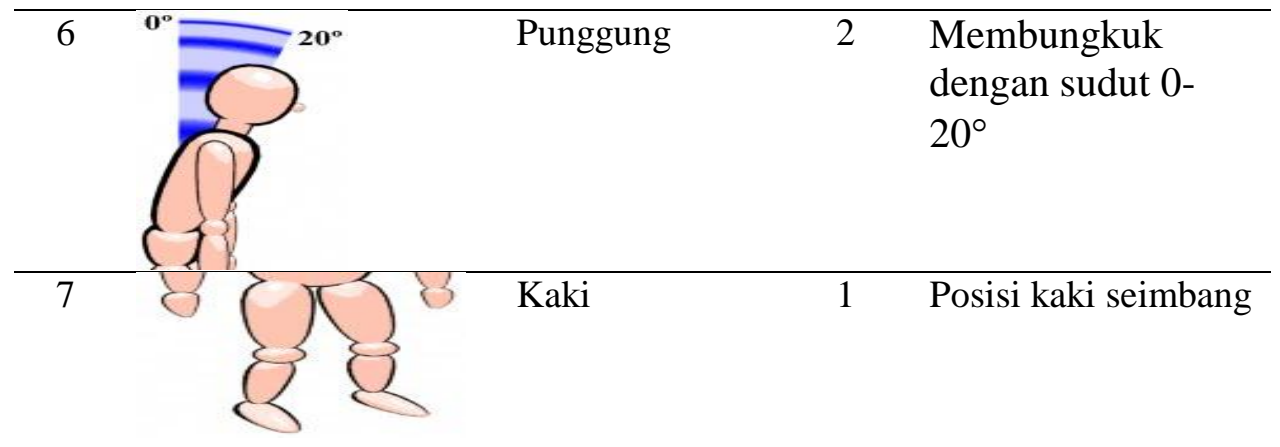

Skor RULA

6

Berdasarkan tabel diatas dapat dilihat scoring general pada daftar aktivitas pekerjaan. Terdapat 4 proses pekerjaan dengan total skor RULA=7 artinya level Risiko Tinggi diperlukan pengendalian risiko saat ini juga yaitu pada tahap Pengambilan Batu, Proses Pengumpulan Batu, Proses Pengangkatan Batu ke Bak Mobil dan proses Pengambilan Pasir.

Proses pekerjaan aktivitas Manual Handling pemuatan batu dan pasir PT. Aura Mandiri Sejahtera dimulai dari mengambil batu dan pasir yang ada dipertambangan kemudian dikumpulkan dan disusun. Setelah batu dan pasir terkumpul selanjutnya diakukan pemuatan batu dan pasir kedalam bak mobil yang dilakukan oleh pekerja. Pemuatan batu dan pasir kedalam bak mobil dilalukan dengan cara manual. Batu dan pasir yang diangkat oleh pekerja kedalam bak mobil mencapai berat kurang lebih 5$25 \mathrm{~kg}$ dan aktivitas ini dilakukan terus menerus sampai dirasa cukup untuk dibawa oleh mobil.

Gerakan yang berulang-ulang jika dilakukan secara terus menerus (setiap beberapa detik) untuk durasi yang lama seperti 8 jam dapat meningkatkan ketegangan otot tendon. Ketegangan otot tendon dapat dipulihkan jika ada jeda waktu istirahat yang digunakan untuk peregangan otot. Dampak dari gerakan yang berulangulang akan meningkat bila gerakan tersebut dilakukan dengan postur janggal dan beban yang berat. Frekuensi gerakan postur janggal $\geq 2 \mathrm{x} /$ menit menyebabkan risiko terhadap siku, bahu, leher, punggung dan kaki dengan pengulangan gerakan yang tinggi dengan menggunakan tenaga yang besar.(Bukhori, 2010)

Sikap kerja adalah posisi relatif bagian tubuh tertentu pada saat bekerja yang ditentukan oleh ukuran tubuh, desain area kerja dan task requirements serta ukuran peralatan/benda lainnya yang di gunakan saat bekerja. Salah satu penyebab utama gangguan otot rangka adalah postur janggal (awkward posture). Postur tubuh yang tidak normal berpengaruh pada terjadinya ketidakseimbangan otot yang di sebabkan penggunaan otot secara berlebihan selain itu juga mengkibatkan otot tidak mampu bekerja secara maksimal. Hal ini menjadi salah satu penyebab terjadinya gangguan 
otot pada pekerja sehingga berdampak pada timbulnya penyakit akibat kerja (PAK) yang tentunya berdampak buruk pada pekerja.(Bukhori, 2010)

\section{SIMPULAN}

Pada penggunaan metode JSA peneliti menemukan bahaya setiap proses pekerjaan yaitu bahaya ergonomic, sedangkan pada saat penentuan risiko kerja peneliti menemukan risiko kerja berupa gangguan otot bagian atas. Ketika dilakukan penilain sikap kerja menggunakan metode RULA penulis menemukan Terdapat 4 proses pekerjaan dengan total skor RULA $=7$ artinya level Risiko Tinggi diperlukan pengendalian risiko saat ini juga yaitu pada tahap Pengambilan Batu, Proses Pengumpulan Batu, Proses Pengangkatan Batu ke Bak Mobil dan proses Pengambilan Pasir

\section{UCAPAN TERIMAKASIH}

Penelitian mengenai pengaplikasian JSA dan RULA pada pekerjaan Manual Handling di PT. Aura Mandiri Sejahtera tidak lepas dari aspek pendukung, antara lain dukungan dari pimpinan dan Pekerja PT. Aura Mandiri Sejahtera yang aktif terlibat dalam penelitian ini sehingga penelitian ini berjalan lancar. Dukungan lain adalah dari tim peneliti, Ketua STikes Indonesia, serta sarana-prasarana penelitian yang juga telah memberikan bantuan moril dan materil sehingga penelitian tidak mengalami kendala yang berarti.

\section{DAFTAR PUSTAKA}

Bortolini, M., Gamberi, M., Pilati, F., \& Regattieri, A. (2018). Automatic assessment of the ergonomic risk for manual manufacturing and assembly activities through optical motion capture technology. Procedia CIRP, 72,
81-86.

https://doi.org/10.1016/j.procir.2018.03 .198

Bukhori, E. (2010). Hubungan Faktor Risiko Pekerjaan Dengan Terjadinya Keluhan Musculoskeletal Disorder (MSDs) Pada Tukang Angkat Beban Pnambang Emas Di Kecamatan Cilograng Kabupaten Lebak Tahun 2010. Hubungan Faktor Risiko Pekerjaan Dengan Terjadinya Keluhan Musculoskeletal Disorders (Msds) Pada Tukang Angkut Beban Penambang Emas Di Kecamatan Cilograng Kabupaten Lebak Tahun 2010, 1-93.

Irennius, G. V., Ahmad, B., Otniel, K., Umi, S., \& Saripati, H. E. (2020). Identifikasi Potensi Bahaya dan Penilaian Risiko Kerja pada Penarik Becak Mesin dengan Metode Job Safety Analysis (JSA). Jurnal TEKESNOS, 2(1). http://114.7.97.221/index.php/tekesnos/ article/view/1538

Salcha, M. A., Kessi, A. T. F., Juliani, A., \& Ahjad, M. (2020). Tingkat Risiko Ergonomi Pada Aktivitas Manual Handling di Gudang Bulog Baru Panaikang I Kota Makassar. Jurnal Mitrasehat, X(1), 100-111.

Siska, M., \& Angrayni, S. A. (2018). Analisis Postur Kerja Manual Material Handling pada Aktivitas Pemindahan Pallet Menggunakan Rappid Upper Limb Activity (RULA) di PT. Alam Permata Riau. Jurnal Sains, Teknologi Dan Industri, 15(2),77-86. http://ejournal.uinsuska.ac.id/index.php /sitekin/article/view/4440 